\title{
A educação física escolar e o projeto político pedagógico: um processo de construção coletiva a partir da pesquisa-ação ${ }^{1}$
}

CDD. 20.ed. 371.12

796.017

\author{
Luciana VENÂNCIO* \\ Suraya Cristina DARIDO** \\ *EMEF Antônio Carlos \\ de Andrada e Silva. \\ SME-SP. \\ **Universidade Estadual \\ Paulista - Campus Rio \\ Claro.
}

\section{Resumo}

0 propósito deste trabalho é apresentar o entendimento que um grupo de professoras de Educação Física que trabalham no Ensino Fundamental na rede municipal de São Paulo tem a respeito do significado do Projeto Político Pedagógico (PPP) no cotidiano escolar. Além disso, tentamos fornecer subsídios para a elaboração e implementação de um PPP e apontar os limites e possibilidades da ação coletiva no contexto escolar. Nesta pesquisa de característica qualitativa foi utilizado o referencial metodológico do tipo pesquisa-ação. Foi feita análise de trabalhos que abordam a temática em questão para elaborar as categorias e encaminhar uma discussão criteriosa à luz do referencial selecionado. Os resultados indicaram que é necessário ressignificar o entendimento da função e papel da escola, da Educação Física enquanto componente curricular e também dos demais componentes curriculares. Destaca-se que é urgente repensar e organizar o espaço escolar a partir de uma perspectiva pedagógica, política e coletiva, para que as ações possam ter sentido e significado para os alunos e professores. Os currículos das instituições formadoras também foram mencionados como importantes para compreender o propósito do trabalho coletivo. 0 PPP pode constituir-se como um legítimo instrumento para participação e envolvimento político e pedagógico dos professores de Educação Física e nortear ações coletivas no cotidiano escolar.

UniteRmos: Educação física escolar; Trabalho coletivo; Formação de professores; Pesquisa-ação.

\section{Introdução}

A partir dos anos 80 do século XX, com o processo de democratização do país e o fim da ditadura, a escola no Brasil passa a ser vista como um espaço possível, de direito, para todos, pelo menos no discurso educacional. No entanto, sabemos que não basta apenas garantir o acesso ao espaço físico, são necessárias também outras medidas, como por exemplo, condiçôes adequadas para que os professores contribuam para uma educação de qualidade para os alunos.

A escola vem envolvendo os agentes educativos em práticas individualizadas, fragmentadas e reafirmadoras de uma sociedade injusta e sem propósito para operar as mudanças necessárias.

Entendemos que uma escola precisa tomar em suas mãos o compromisso político e pedagógico para garantir uma educação de boa qualidade, caminhar em busca de uma autonomia crítica e coletiva, e para isso a integração de saberes e atitudes políticas dos educadores acena como uma possibilidade de transformação.
As barreiras que os professores, trabalhadores da educação, enfrentam para refletir criticamente a respeito do espaço coletivo escolar são inúmeras tais como currículo organizado por disciplinas; acúmulo de jornadas de trabalho; ausência de critérios para coordenação pedagógica e articulação das ações e práticas pedagógicas; direção/gestão escolar verticalizada e projetos pedagógicos desvinculados das realidades cotidianas além de outros.

O contexto histórico de desenvolvimento da instituição e de suas práticas é complexo e contraditório, permeado por questóes que remetem à reprodução de desigualdades e conhecimentos baseados em princípios e interesses burgueses.

Esse contexto reforça práticas alicerçadas em paradigmas positivistas de educação e dificulta a compreensão do que pode ser de fato o espaço escolar e sua cultura. Essa condição posta estabelece um "habitus" (Bourdieu \& PAsSeron, 1992), no 
qual seus agentes estão mergulhados em um espaço individualizado de submissão e poder hierárquico.

A estrutura organizacional da escola apresenta-se como uma ameaça ao trabalho crítico coletivo, pois pressupõe um "locus" de resistência às tentativas de mudanças, diante dos tempos e espaços cristalizados. Nesta perspectiva, o trabalho coletivo na escola pressupõe romper com os paradigmas da individualidade, da falta de objetividade, e aponta para um paradigma da coletividade e busca de objetivos comuns, coerentes, relevantes e dialógicos.

LiBÂNEO (1998) discute as transformaçōes do papel da escola e dos professores na sociedade pós-industrial, chamando a atenção para a influência nas várias esferas da vida social, econômica, política e cultural, afetando também as escolas e o exercício profissional da docência.

Frigotto (1996) e SACRISTÁn (1999) apontam que a transformação geral da sociedade repercute na educação, nas escolas e na organização do trabalho dos docentes. Os autores nos alertam que tal repercussão tem se caracterizado pela subordinação da educação à economia e ao mercado, sendo mínima ou inexistente a preocupação com a desigualdade e o destino social das pessoas. Neste sentido, não se pode deixar de investir na proposta de uma escola democrática que privilegie conhecimentos, habilidades e valores necessários para a sobrevivência e que promova mudanças no mundo complexo de hoje.

Como afirma Freire (2001), a prática educativa considerada como prática social, em sua riqueza e complexidade é fenômeno típico da existência, por isso mesmo, fenômeno exclusivamente humano. Ensinar e aprender para o educador são momentos do processo maior de conhecer. Por isso deve envolver busca, curiosidade, equívoco, acerto, erro, serenidade, rigorosidade, sofrimento, tenacidade, mas também satisfação, prazer e alegria.

A escola precisa abandonar, no entendimento de LiBÂNEO (1998), a ideia de ser simplesmente uma agência transmissora de informação e transformar-se num local de análises e proposições críticas, no qual o conhecimento elaborado possibilite a atribuição de significados concretos.
Professores com visões de mundo diferentes, mergulhados em ambientes de tensão, conflitos e complexidade terão condiçōes de romper com os condicionantes de uma instituição que busca - mas não tem conseguido - superar a individualização do trabalho docente? A Educação Física enquanto componente curricular terá condiçôes de contribuir a partir da perspectiva de sua matriz pedagógica?

Enfatizamos que é necessário analisar e compreender a organização do trabalho pedagógico, no sentido de se gestar uma nova organização que reduza os efeitos de sua divisão do trabalho, de sua fragmentação e do controle hierárquico.

Nosso trabalho por considerar a escola, um dos espaços com condições para romper com esses dilemas, principalmente quando busca a valorização dos diferentes saberes no trabalho coletivo, chama a atenção para a responsabilidade e compromisso também da Educação Física nessa empreitada. Considerada na legislação em vigor como componente curricular, cabe a tal área e ao professor que a representa buscarem mudanças coletivas nas práticas pedagógicas (SAnches Neto, VenÂncio, OKimura \& UlasowicZ, 2006) ancoradas em um Projeto Político Pedagógico (PPP) propositivo e coerente (MOTA e Silva \& Venâncio, 2005; Venâncio, 2005a).

VeIga (1998) considera o PPP um instrumento de luta a ser utilizado pela escola, capaz de nortear o enfrentamento das dificuldades do trabalho pedagógico de forma coletiva.

A construção do PPP é uma forma de contrapor-se à fragmentação do trabalho pedagógico, à dependência dos órgãos e instituiçōes acadêmicas que regulam estrategicamente o ensino e o trabalho na escola.

O propósito deste trabalho é apresentar o entendimento a respeito do significado do PPP atribuído por um grupo de professoras de Educação Física que trabalham em escolas na rede de ensino público do município de São Paulo. Além disso, procuraremos fornecer subsídios para a elaboração e implementação de um PPP e apontar os limites e possibilidades da ação coletiva no contexto escolar.

\section{Procedimentos metodológicos}

Dentre os vários tipos de pesquisa que aparecem associados à abordagem qualitativa, este optou pelo referencial metodológico do tipo pesquisa-ação.

Para Thiollent (2000), a pesquisa-ação permite conceber e realizar em estreita associação com uma ação ou com a resolução de um problema coletivo, no qual pesquisadores e participantes estão envolvidos de modo cooperativo ou participativo.

ELLIOTT (1998) aponta duas dimensōes importantes da pesquisa-ação e sua constituição enquanto 
prática reflexiva: a dimensão ética e a dimensão filosófica. A dimensão ética determinará o curso da ação considerando a prática e interpretação dos próprios valores, cuja reflexão sobre os meios não podem estar separados da reflexão sobre os fins, revestindo-se neste caso de uma dimensão filosófica. A pesquisaação é uma reflexão ética que chama a atenção sobre a importância que têm os dados empíricos como fundamento de uma melhora reflexiva da prática.

Para ElLIOTT (1993), as características mais relevantes da pesquisa-ação são assim descritas:

- Uma estratégia vinculada à formação das pessoas envolvidas;

- Priorizam-se as atuações históricas e situações sociais que são percebidas pelos educadores como problemáticas e passíveis de mudança;

- Compreende o que está ocorrendo a partir da perspectiva dos envolvidos no processo: professores, alunos, pais, coordenação e direção;

- Re-elabora os contextos da situação por meio do diálogo para estabelecer interrelações com os mesmos.

Neste caso cabe ao pesquisador, numa atitude reflexiva diante dessa situação, colaborar com os professores para que estes reflitam a respeito das atitudes que estão sendo tomadas em cada escola e entendam a complexa dinâmica escolar, na perspectiva de não fazer uma reflexão ingênua, sem sentido, sem pertencimento, sem significado, mas uma reflexão sobre a necessidade de entender mais o espaço escolar, sua organização, sua estrutura e seus contextos reais nos quais são travados embates diversos permeados por relações de poder.

Organizamos um grupo com três professoras ${ }^{2}$ que lecionavam para os ciclos I ( $3^{\mathrm{a}}$ e $4^{\mathrm{a}}$ séries) e II $\left(5^{\mathrm{a}}\right.$ à $8^{a}$ séries) do ensino fundamental da rede pública municipal de São Paulo e mais uma professorapesquisadora, a primeira autora desse artigo. A respeito do tempo de trabalho na rede municipal, duas professoras trabalhavam há nove anos e uma há um ano. Foram realizados sete encontros durante o ano de 2004, planejados com a intenção de discutir e dialogar a respeito do problema apresentado pela pesquisa e vivenciado pelas professoras no cotidiano da escola.

Os encontros foram orientados a partir dos temas: escola e educação (visão dos participantes), organização dos conteúdos/conhecimentos dos componentes curriculares da escola, currículo escolar, projeto político pedagógico, Educação Física escolar e PPP e, avaliação dos encontros. Organizamos cinco categorias a partir dos encontros tendo como referência as situações vividas pelas professoras em seus cotidianos específicos:

\section{Escola: necessidade de conhecimento - que espaço é esse?}

Conhecer a dimensão física do espaço escolar em princípio parece não ser tão importante, no entanto, durante os encontros as professoras apontaram que é de suma importância, pois é nesse espaço que as relaçōes sociais acontecerão e consequentemente o resultado dessas relaçôes interferirá significativamente no processo educativo, gerando também tensões e conflitos internos.

Para as professoras a concepção arquitetônica das escolas na qual trabalham limita o trabalho desenvolvido nas aulas de Educação Física. O próprio espaço físico torna invisível as ações que são desenvolvidas e desencadeadas no cotidiano escolar. A quadra, espaço físico que tradicionalmente é caracterizado como pertencente à Educação Física, normalmente fica em área restrita ao professor e aos alunos que frequentam as aulas e uma maioria significativa de professores, funcionários e outros membros da comunidade escolar não conhecem ou não sabem o que é realizado nesse espaço, reforçando uma visão restrita, muitas vezes associando o espaço única e exclusivamente para jogar bola e a realização de campeonatos esportivos.

AlarCáo (2001), considera a escola um lugar, um edifício circundado por alguns espaços abertos. Entretanto, às vezes, depara-se a pensar se a arquitetura escolar não se encontra defasada em relação às concepções de formação, às formas de gestão curriculares e às exigências do relacionamento interpessoal neste início de milênio.

Espaço caracterizado também por relações de poder conflituosas, com ausência de proposiçóes que discutam a diversidade dos aspectos éticos, étnicos, religiosos, sociais, econômicos, culturais e de gênero que imprimem suas marcas dentro e fora da sala de aula ou da quadra constituindo um espaço de culturas próprias, porém desarticuladas e individualizadas.

As relações de poder que acabam se estabelecendo dentro deste espaço, reforça a imposição e reprodução de valores e condutas de uma sociedade dividida em classes (Bourdieu \& Passeron, 1992) e parece manter-se, quando o significado atribuído ao espaço não é percebido na sua totalidade, podendo gerar inclusive condutas simbólicas de violência.

\section{Ambiente de trabalho e formação: rompimento de práticas individualizadas}

Para que o processo de tomada de decisão e consciência inclusive na organização do ambiente 
de trabalho e formação seja iniciado, existe a necessidade de cada escola procurar mecanismos próprios visando à participação de todos os envolvidos no processo educativo.

Para as professoras envolvidas na pesquisa o ambiente de trabalho não fornece condições para o diálogo aberto, consciente e crítico entre aqueles que trabalham na escola. $\mathrm{O}$ trabalho desenvolvido nas aulas de Educação Física fica restrito aos professores responsáveis que raras vezes têm a oportunidade de socializar com os demais companheiros da escola. Os motivos são os mais diversos, tais como horários incompatíveis, pouco entendimento da área, insegurança e incerteza, inexperiência, desmotivação e descrédito no fazer cotidiano e lacunas percebidas na formação inicial e permanente.

Uma das professoras mencionou inclusive que na escola na qual trabalha há outros professores de Educação Física que tiveram uma formação inicial pautada em pressupostos técnico-esportivos e não se preocupam em participar dos encontros de formação coletivos que acontecem na escola. Os planejamentos da área, segundo a professora, são feitos por cada um dos professores e quando tem necessidade de expor uma dificuldade pedagógica para o coletivo da escola, não encontra respaldo, e resolve de forma solitária.

As professoras, provavelmente em função da história e do entendimento equivocado da disciplina, enfrentarão muitas dificuldades para romper com circunstâncias preconcebidas no trabalho escolar, que exigirá delas muita persistência, envolvimento e compromisso político e pedagógico.

Segundo IMBERnón (2002), nos últimos tempos questionaram-se muitos aspectos da educação (éticos, coletivos, comunicativos, comportamentais, emocionais) que visavam uma educação democrática. Assim, continua ele, começou-se a valorizar a importância do sujeito, de sua participação e, portanto, também a relevância que a bagagem sócio-cultural (a comunicação, o trabalho em grupo, a tolerância, a elaboração conjunta de projetos e a tomada de decisões democráticas) assume na educação e na formação docente.

A prática de projetar e planejar coletivamente nas escolas não é uma regra. Nossas açōes educativas estão mais voltadas para a adaptação do que para a criação, devido às condições de trabalho, características da formação dos professores e visões de mundo diferenciadas. Sabemos da necessidade de orientar o trabalho coletivo e pedagógico segundo um propósito, porém, agimos como se nada soubéssemos ou não quiséssemos. Condutas tomadas que é fruto da complexidade que circunda a escola, os professores, os interesses individuais e os fatores externos. Segundo as professoras algumas medidas arbitrárias de órgãos que regulam os sistemas de ensino influenciam de forma negativa alguns procedimentos autônomos tomados pelas escolas nas quais trabalham.

NÓVOA (1995) considera o projeto um caminho para tratar a formação do professor, possibilitando assim, espaço para formação do profissional reflexivo. Falar de formação de professores é falar de um investimento educativo dos projetos de escola, em que o desafio consiste em conceber a escola como um ambiente educativo, onde trabalhar e formar não sejam atividades separadas.

\section{Seleção e organização dos conteúdos na escola}

Os debates a respeito da interdisciplinaridade, pedagogia de projetos, aprimoramento das práticas de planejar e executar as ações educativas, preocupação com a construção de propostas eficazes e eficientes que identifiquem e dêem coerência às práticas pedagógicas, são sintomas que caracterizam a necessidade que vem ocorrendo no modo como entendemos e precisamos entender a escola, a organização dos tempos e espaços e também a seleção dos conteúdos.

A seleção de conteúdos nas escolas onde as professoras lecionam apresenta algumas características já conhecidas por todos aqueles que já passaram por escolas como professores. Segundo elas, pouco se sabe sobre o que se ensina, por que, para quem e para que determinados conhecimentos e conteúdos são selecionados. Cada professor tem a liberdade de selecionar o que bem entender para compor o rol de conteúdos que são ensinados. Não há consenso, nem interesse coletivo para almejar objetivos comuns.

No entanto, acreditamos que devido às necessidades de se justificar a função da escola, do ensino e visando construir uma identidade individual e coletiva para o desenvolvimento profissional, as preocupações com o que está sendo ensinado começa a ser uma inquietação também dos próprios educadores, segundo os relatos apresentados.

Os conteúdos selecionados pelas professoras são na sua maioria relacionados às modalidades esportivas tradicionais: futsal, voleibol, basquete e handebol. Porém, o atletismo, esportes radicais, natação, a dança, a ginástica, capoeira, lutas e conhecimento sobre o corpo começam a ser inseridos nas aulas de Educação Física e discutidos com os alunos através do planejamento participativo e também outros fenômenos que influenciam as aulas como a mídia e as questôes de gênero. 
Tais aspectos são relevantes para a Educação Física e têm sido uma preocupação para a organização dos conteúdos e mudança da prática pedagógica na escola (SANChes Neto et al., 2006). No entanto, essa mudança na perspectiva de diversificar os conteúdos precisa ser compartilhada com outros professores de Educação Física e também com professores de outras áreas do conhecimento.

Segundo os PCN (BRASIL, 1998), os conteúdos são os meios pelos quais o aluno pode analisar e abordar a realidade de maneira a construir uma rede de significados em torno do que se aprende na escola e do que se vive. O que se pretende segundo Vale (1999) é formar um aluno competente no uso do conhecimento sistemático e crítico em relação ao contexto. $\mathrm{O}$ aluno também deve ser consciente no uso de diferentes linguagens, criativo, autônomo, capaz de usar a liberdade com responsabilidade em decorrência da consciência dos limites e emancipado pela capacidade de analisar e julgar as questões de modo reflexivo.

\section{O papel do Coordenador Pedagógico na perspectiva de ações coletivas}

Segundo as professoras, os professores de Educação Física e dos demais componentes curriculares, sabem como é difícil enfrentar as barreiras e incertezas do cotidiano no contexto escolar. Na medida do possível aproximam-se nos ambientes de trabalho daqueles que tem mais afinidades pessoais.

Destacam que essa situação e a relação que se estabelece no interior de cada escola, muitas vezes pautadas em relaçóes de amizade revelam a fragilidade dos aspectos profissionais, pedagógicos e políticos, que acabam prejudicando sobremaneira a busca pela boa qualidade de ensino, a percepção das necessidades reais dos alunos no que se refere à aprendizagem e a identidade profissional coletiva.

A ideia de relação presente na vida humana nos aponta uma competência que, além de ser construída, é também compartilhada. Uma pessoa não pode ser humana sozinha. Do mesmo modo, uma pessoa não pode ser competente sozinha.

Cabe também ao coordenador pedagógico no entendimento das professoras estabelecer prioridades no projeto de formação e articulação das ações realizadas pelos professores. Mencionam os horários coletivos, que são espaços de conquistas na rede municipal de ensino e poderiam encaminhar positivamente as propostas de ações realizadas junto aos alunos e demais compartilhar com os demais segmentos da escola.
A coordenação exerce a função de articuladora pedagógica entre os professores, ressaltam as professoras. E todos que participam dos horários coletivos precisam sentir-se motivados e corresponsáveis pelas ações desenvolvidas na escola.

Para Rios (1995), a qualidade do trabalho educativo não depende apenas de uma única pessoa ou área de conhecimento - define-se na relação com os outros. As condiçôes para a realização de um trabalho competente estão na competência do profissional e na articulação dessa competência com os outros e com os contextos do ambiente de trabalho.

\section{O grande desafio: elaboração e implementação de PPP}

A decisão de ampliar as relações humanas no ambiente escolar saindo de um processo de individualidade para uma coletividade reflexiva é um desafio enorme que os educadores deverão superar para elaborar e gestar um PPP (VENÂNCIO, 2005b).

Não será novidade para ninguém que tal intenção, no âmbito coletivo exigirá de cada agente social um maior compromisso e comprometimento. É importante ressaltar, por exemplo, que durante esse processo as diferenças virão à tona, e a partir delas serão traçadas ações comuns que deverão ser planejadas, executadas, avaliadas e replanejadas com constância e consciência.

Durante os encontros as professoras sugeriram alguns pontos de reflexão para auxiliar o início do percurso sempre constante para enfrentar tal desafio:

- Diagnóstico e caracterização da comunidade escolar (entrevistas, palestras, encontros, questionários, assembleias etc);

- Comunidade escolar: constitui-se de pais, alunos, professores, funcionários, direção, coordenação pedagógica, moradores do entorno, etc;

- Discussão: sobre a função e papel da escola na atualidade;

- Definição e caracterização do perfil e necessidades dos alunos de cada escola;

- Definição e caracterização do perfil do corpo docente, coordenação e direção;

- Definição da concepção de educação, visão de homem e sociedade;

- Definição de objetivos específicos e gerais - finalidades de cada componente curricular;

- Estabelecimento de diretrizes norteadoras para enfrentamento de questōes atuais (por exemplo: inclusão, autonomia, qualidade da educação, formas de gestão da escola etc.); 
- Escolhas dos componentes curriculares ou áreas de conhecimento que estabelecerão e constituirão o currículo;

- Tempos e espaços: desdobramentos e organização dos componentes curriculares com critérios próprios, carga horária, ciclos, séries/anos, quantidades de turnos ou períodos de funcionamento;

- Planos de ensinos interdisciplinares (objetivos, habilidades e competências a serem desenvolvidas, conteúdos mais relevantes, metodologia de trabalho, formas de avaliação);

- Articulação e organização interdisciplinar entre os espaços existentes na escola: biblioteca/sala de leitura, sala de vídeo, laboratório de informática, laboratório de ciências, anfiteatro, etc;

- Elaboração de projetos interdisciplinares;

- Periodicidade das reuniōes pedagógicas com a presença dos pais e alunos;

- Fortalecimento e ampliação dos espaços de formação do corpo docente (coletivo e individual);

- Definição da participação das instituiçôes democráticas: Conselho de Escola e Grêmio Estudantil - Decisões Colegiadas;

- Definição de prioridades para utilização dos recursos disponíveis (financeiros e materiais);

- Participação de alunos e professores em fóruns, seminários, congressos, conferências, financiados pela própria instituição ou por órgãos competentes;
- Parcerias com outras instituições (universidades, ONGs, fundações, institutos etc.);

- Calendário escolar definido pela própria escola;

- Definição de um instrumento de avaliação do PPP, elaborado pela própria comunidade escolar como forma de possibilitar a autonomia e flexibilidade nas mudanças e rumos do projeto - da própria escola.

As sugestôes feitas pelas professoras caminham na direção de que a definição, construção e implementação de um PPP pressupõem um trabalho em conjunto, coletivo, que visa o engajamento e comprometimento em busca da qualidade na formação do aluno e do trabalho do professor e não se restringe a uma mera reprodução de conhecimentos ou ações, visto que atitudes e ações isoladas inibem a percepção de problemas coletivos.

Segundo Kramer (1997), uma nova proposta será um desafio e uma aposta em um novo currículo, que contenha nos objetivos do projeto político pedagógico, um conceito de cidadania, de educação e cultura. Para a autora, não se pode trazer respostas prontas para serem implementadas através de propostas sem sentindo e significado, quando se tem em mira a construção de uma escola e uma sociedade que considere a justiça social um bem comum.

\section{Os conceitos e contextos do trabalho coletivo}

Torna-se relevante analisar que os conceitos veiculados nos meios educacionais a respeito de PPP, nem sempre gozam de unicidade de sentido e significado. São compreendidos e interpretados de diferentes formas, assumindo múltiplas dimensões. E, de fato, são múltiplas as conotações atribuídas ao termo.

A dinâmica escolar, segundo as professoras, transita entre o PPP "formal" (aquilo que está documentado, escrito; enfim, o discurso da instituição) e PPP "em ação", ou seja, como funciona o projeto na realidade.

A Lei de Diretrizes e Bases - LDB no 9394/96 (Brasil, 1996) surgiu dentro de um contexto de transformações rápidas e contínuas, caracterizando a reforma do sistema educacional nacional, que implicou em mudança na concepção do processo de ensino-aprendizagem, conforme os princípios, fins e objetivos sancionados em 20/12/1996, considerando as alteraçôes sofridas em artigos, parágrafos e decretos até 2004.
A LDB, mencionada por diversas vezes pelas professoras, trouxe uma série de alterações e pressupostos, dentre as quais podemos destacar: a mudança da estrutura didática, a autonomia dada às escolas e aos sistemas de ensino federal, estadual, municipal e privado, e o enfoque direcionado à formação do cidadão. Apesar do destaque dado na LDB à escola enquanto instituição que goza de certa autonomia, segundo as professoras os princípios apresentados na LDB são pouco ou quase nada aproveitados pelas escolas, provavelmente pelo desconhecimento ou pouco entendimento da sua função.

CURY (1997) designa a LDB como uma "polifonia acromática”, por considerar que muitas vozes foram mascaradas, silenciadas, por considerar que existem vozes recessivas e outras dominantes e pela incongruência do conjunto da lei. Mas ressalta que o respeito à lei, na perspectiva do bem comum, é uma das formas mais avançadas do estado democrático e de direito, por isso cumpre-nos, sob a lei, encontrar 
os caminhos de emancipação que a mesma pode propiciar àqueles que se recusam a viver na anomia. Como forma de alcançar essa emancipação destaca o caráter flexível da lei no que se refere à estrutura e ao funcionamento da educação nacional, e acrescentamos às palavras do autor que, um estado democrático e de direito não está livre de conflitos.

A questão da construção do projeto pedagógico aparece na LDB, com destaque para a necessidade da participação da equipe escolar na construção do mesmo e a autonomia da escola para concebê-lo, viabilizá-lo, implementá-lo e avaliá-lo. Segundo GADOTTI (2001), a legislação dá alguns passos embora tímidos na direção da descentralização e da autonomia. Vejamos alguns artigos da LDB (BRASIL, 1996) que tratam desta temática:

Artigo 12 - Os estabelecimentos de ensino, respeitados as normas comuns e as do seu sistema de ensino, terão a incumbência de:

I - elaborar e executar sua proposta pedagógica;

VII - informar os pais e responsáveis sobre a frequência e o rendimento dos alunos, bem como sobre a execução de sua proposta pedagógica;

Artigo 13 - Os docentes incumbir-se-ão de:

I - participar da elaboração da proposta pedagógica do estabelecimento de ensino;

II - elaborar e cumprir plano de trabalho, segundo a proposta pedagógica do estabelecimento de ensino;

Artigo 14 - Os sistemas de ensino definirão as normas da gestão democrática do ensino público na educação básica, de acordo com as suas peculiaridades e conforme os seguintes princípios:

I - participação dos profissionais da educação na elaboração do projeto pedagógico da escola;

II - participação das comunidades escolar e local em conselhos escolares ou equivalentes.

A LDB (BRAsIL, 1996) atual trouxe alguns avanços para a Educação Física escolar. Considerada um componente curricular obrigatório e corresponsável pela elaboração e construção da proposta pedagógica da escola.
Projeto vem do latim "projectu", do verbo "projicere”, que significa lançar para diante, indicando a ideia de futuro, algo que está por vir, por acontecer. A literatura aponta o conceito de projeto implicado em um processo de criação, transformação, mudança de algo que está por vir, promessa para o futuro, empresa, desejo, antecipação, finalidade, tensão, incertezas, ação, meio que permite ao homem ser parte da história. Ao projetar o ser humano concebe um futuro desejado, e pode vir a interferir na história, uma vez que possui a capacidade de transformar e provocar mudanças.

Apesar de ter uma significativa produção a respeito da importância do PPP para as escolas, as professoras mencionaram que raríssimas vezes esse tema foi abordado durante a formação inicial, aliás, segundo elas, as disciplinas de características didático-pedagógicas enfatizavam aspectos mais técnicos do ensino, tal como organização dos alunos nas aulas. Aspectos que envolviam discussão pertinente de como agregar o aspecto político ao aspecto pedagógico não foram ressaltados.

Um PPP é a realização de um plano de ação, a partir de ideais de educação, tendo como elemento básico as relações humanas, ou seja, o ser humano agindo segundo seus interesses coletivos.

Para Palma Filho (1998) as diferentes concepções de educação, mesmo implícitas, sempre estão presentes no planejamento educacional e curricular. Quando a escola seleciona objetivos, conteúdos, metodologia e critérios de avaliação do aprendizado, está optando por um determinado projeto educacional, que de forma alguma é neutro em relação à cidadania.

Atualmente o PPP ocupa um lugar de destaque no âmbito das discussões sobre a educação. É considerado, por aqueles preocupados com a formação docente, fator importante no processo de desenvolvimento educacional e profissional, com vistas a fazer do espaço educacional um espaço de ressignificar as ações com possibilidade de mudança na realidade.

\section{O PPP e a Educação Física Escolar: apontamentos de alguns autores e documentos da área}

A Educação Física escolar enquanto componente curricular é um dos responsáveis pela formação do cidadão, e por isso, deve participar das discussões referentes à construção do PPP e compartilhar a sua implementação. O professor de Educação Física, que é membro do coletivo escolar, tem tarefas e responsabilidades a cumprir e deve estar comprometido com o seu papel pedagógico e político.

Apresentaremos alguns trabalhos realizados por pesquisadores da Educação Física que apresentam os termos projeto político-pedagógico, proposta pedagógica, planejamento escolar, planejamento curricular, 
projeto, considerando a escola como seu espaço de desenvolvimento. Vale destacar que as professoras participantes conheciam os referenciais que selecionamos também por meio de palestras, congressos, seminários, aliás, três professoras tiveram aulas na graduação ou pós-graduação com alguns dos autores.

Cabe ressaltar, no entanto, que a maioria dos estudos não tiveram como objetivo principal discutir/ relacionar a Educação Física, escola, professor com as questōes relacionadas ao PPP. Entretanto, como tais temas apareceram nos estudos, consideramos importante arrolar alguns aspectos destes trabalhos, pois os mesmos contribuem para dar relevância ao que apresentamos neste artigo.

Freire (1989) em sua obra Educação de corpo inteiro, cuja proposta encontra espaço principalmente para a Educação Infantil e os primeiros anos do ensino fundamental destaca como finalidade a construção do conhecimento por parte do educando, sendo o lúdico, a cultura popular, a brincadeira e o jogo temas principais a serem considerados e desenvolvidos na proposta pedagógica da escola.

No entendimento de Freire, se a escola tem uma proposta pedagógica, os conteúdos do jogo e do brinquedo não podem ser desconsiderados. A proposição apresentada permite uma integração com uma proposta pedagógica ampla e integrada da Educação Física nos primeiros anos de escolarização.

Em Metodologia do ensino de educação física, Soares, Taffarel, Varjal, Castellani Filho, Escobar e BRACHT (1992), enfatizam a importância de uma Educação Física escolar comprometida com um projeto político pedagógico capaz de transformar o homem e a sociedade, a partir da reflexão sobre a cultura corporal, numa perspectiva crítico-superadora. $\mathrm{O}$ objetivo da concepção é facilitar a reflexão e a prática pedagógica dos professores do magistério, do ensino fundamental e médio. Os autores apontam o currículo como sendo a materialização do PPP nas práticas dos componentes curriculares.

A legitimidade ou relevância de um componente curricular só se constitui na perspectiva de um currículo que permita levar o aluno a refletir sobre o objeto de estudo de cada área. Não perseguir isso compromete a perspectiva de totalidade dessa reflexão.

Todo educador segundo SOARES et al. (1992), deve ter definido o seu PPP, pois, será ele que orientará as práticas e ações desenvolvidas no interior de cada sala de aula, a relação professor-aluno, os conteúdos mais relevantes e a metodologia mais adequada, bem como os valores e o pensamento que desenvolve nos alunos.
Tal definição permitirá, no entendimento dos autores, a realização do projeto de escolarização do homem, constituído por três pólos: o trato com o conhecimento, a organização e a normatização escolar. Esses pólos, construídos sob princípios sociológicos, filosóficos, políticos, antropológicos, entre outros, se articulam afirmando e negando ao mesmo tempo concepções de homem e cidadania, educação e escola, sociedade e qualidade de vida, explicitando a direção do currículo. Essa direção se concretizará de maneira implícita ou explícita, dependendo do movimento político e social realizado por professores e alunos, na afirmação de seus interesses e projetos, ou seja, explicita a concepção de um PPP.

Os autores destacam que os conhecimentos são os temas da cultura corporal tratados na escola através do jogo, esporte, capoeira, ginástica e dança, expressados de maneira significativa, dialética e intencional, como forma de compreender e transformar o homem e as estruturas sociais.

Os autores apontam também que as implicações metodológicas do fazer coletivo considerando a avaliação dos conteúdos em toda a instituição devem estar submetidas aos princípios do PPP. No planejamento e na tomada de decisão coletiva, os responsáveis pela prática pedagógica precisam estar envolvidos no processo avaliativo da Educação Física, buscando-se a coerência das ações com o projeto pedagógico da escola.

Isso significa que, constantemente devem ser analisados os critérios de seleção, organização, transmissão e avaliação de conteúdos e metodologias do ensino, buscando referenciá-los nos interesses individuais e coletivos, no projeto pedagógico e no projeto histórico (SOARES et al., 1992).

DAOLIO (2000) no livro Da cultura do corpo buscou compreender as representaçóes dos professores da área sobre sua prática profissional, tendo a cultura, os gestos e as técnicas corporais como preocupação.

$\mathrm{O}$ autor surpreendeu-se com a quantidade de planejamentos arquivados ao visitar na época uma delegacia de ensino, para coletar os dados de sua pesquisa. Sua intenção ao escolher os planejamentos era de encontrar escolas com o perfil de classe social necessário para sua pesquisa.

Vale situar o leitor, que se espera da escola como um todo que aponte em seu projeto qual é o perfil da comunidade que será atendida. DAOLIO percebeu que, muitas vezes, as escolas não consideram o local onde estão inseridas e não sabem para quem prestam serviço, não explicitando isso nos seus projetos.

Os documentos arquivados não caracterizam a realidade escolar, apresentam um conjunto 
de informes administrativos ou de intenções educacionais indefinidas. Os planejamentos caracterizavam uma formalidade burocrática e não justificavam as reais intenções das escolas.

Bетті (1998) em seu livro Janela de vidro, cujo objetivo foi, por meio da hermenêutica, interpretar o discurso da televisão sobre o esporte, refletindo criticamente sobre suas repercussôes na Educação Física, faz dentre outras perguntas uma que nos parece significativa e contribui para este trabalho: Que projeto de Educação Física essa interpretação nos autoriza a conceber? (p.12).

Segundo o autor desde os anos 80 do século XX, o debate sobre o que é Educação Física é intenso. Aponta a diminuição do impacto das concepções militar e médica e o surgimento de novas propostas a partir do processo de redemocratização do país, novas idéias, novos fundamentos e novas proposições pedagógicas ocuparam espaços e agitaram a área.

Neste trabalho o autor recorre a uma das matrizes - que gera os diversos entendimentos a respeito da Educação Física - a matriz pedagógica. Para ele a Educação Física deve ser entendida e concebida como prática pedagógica. Tal matriz deve ser considerada quando se faz um questionamento sobre o papel social atribuído a área.

Nos PCN (Brasil, 1998), a questão da autonomia da escola em construir sua própria proposta pedagógica é ressaltada, tendo em vista que seu contexto é amparado pela LDB (BRASIL, 1996) e que orienta a necessidade da Educação Física estar integrada à proposta da escola.

Segundo os PCN (Brasil, 1998), a Educação Física possui uma história de pelo menos um século e meio no mundo ocidental moderno, tem uma tradição e um saber-fazer ligados ao jogo, ao esporte, à dança, à luta, e à ginástica e, a partir desses conteúdos tem procurado a formulação de um recorte epistemológico próprio, em que se organizam os elementos da cultura corporal de movimento.

BRACHT (2001) em um rápido resgate histórico procura identificar os elementos que fizeram da Educação Física um importante constituinte do projeto educacional liberal burguês e discute elementos para uma possível inserção da Educação Física num projeto pedagógico de caráter crítico. Esse ponto é que nos interessa ressaltar.

Os elementos a que se refere BRACHT que sustentavam a Educação Física são a aptidão física como garantia de uma maior produtividade no trabalho; as questôes de saúde, em que o Estado passa a ser o grande responsável, pelas campanhas de massificação esportiva como o programa Esporte para Todos, cuja finalidade era diminuir os custos do sistema de saúde; visão médica do corpo, cuja comparação deste com à máquina fez inserir a biologização do corpo e estabeleceu o entendimento oficial na sociedade; a idéia de trabalho em oposição ao lazer sendo este apenas uma recompensa do primeiro e ocupação saudável do tempo ocioso; e o esporte, elemento mais recente em função da sua relevância social e importância política e econômica.

Bracht acredita que a Educação Física é responsável por inserir as pessoas no universo da cultura corporal de movimento para que possam atuar de forma autônoma e crítica também nos espaços de lazer, e isso consequentemente se torna uma questão importante no âmbito educacional.

Como componente curricular a Educação Física deverá possibilitar que os alunos tenham as experiências mais significativas, para que a partir delas compreendam a linguagem corporal, respeitem o outro e a si próprios. Desta forma o professor de Educação Física deve propor um plano que considere as características e necessidades dos estudantes, e este deve ir ao encontro dos princípios do projeto pedagógico de cada escola.

PAES (2002) considera a pedagogia dos esportes, os jogos coletivos e seu referencial metodológico como facilitadores no processo de educação de crianças e jovens, sendo o ensino formal - escola, o cenário para o desenvolvimento de uma proposta pedagógica para a Educação Física.

Segundo o autor, a modernidade exige que o professor de Educação Física compreenda o esporte e a pedagogia de forma mais ampla, pois é preciso ir além da técnica e promover a integração no ambiente escolar, pois só assim será possível a construção de uma proposta pedagógica que considere princípios essenciais para a educação dos alunos. O referencial metodológico da pedagogia dos esportes deverá responder a quatro questôes: $\mathrm{O}$ que ensinar? Quando ensinar? Como ensinar? Em que medida o esporte poderá contribuir junto ao processo educacional do ser humano? (PAES, 2002, p.91).

$\mathrm{O}$ autor ainda adverte que a falta de planejamento leva o professor a trabalhar de maneira isolada. No caso da educação formal a situação fica prejudicada, pois, a prática do esporte é feita de forma descontextualizada com o projeto pedagógico da escola, resultando em uma fragmentação entre a Educação Física e os outros componentes curriculares, causando perdas significativas ao aluno.

Ao mencionar rapidamente os autores e seus trabalhos ressaltamos que o termo projeto 
pedagógico, já faz parte da preocupação da Educação Física escolar, no entanto precisa passar por uma e ressignificação, e para que isso ocorra é necessário aprofundarmos a compreensão a respeito das possibilidades dos conteúdos selecionados, metodologias utilizadas na área, tendo em vista a participação efetiva na elaboração e implementação de um projeto maior.

\section{Conclusão}

$\mathrm{Na}$ realização desta pesquisa procuramos durante todo o processo, dialogar com a literatura e com as experiências das professoras envolvidas.

Quando se decide realizar uma pesquisa qualitativa do tipo pesquisa-ação, a grande preocupação dos envolvidos deve estar norteada problematização de questóes pertinentes, e necessidade de minimizar os problemas enfrentados no cotidiano escolar e encaminhar possíveis soluçóes.

A maneira de conduzir a pesquisa estabelecendo uma relação de parceira colaborativa entre o grupo foi justamente uma característica que avaliamos como positiva durante o processo. Nesta perspectiva, a participação das professoras concretizou-se a partir das experiências individuais e coletivas, desencadeando um diálogo que problematizava a escola pelo olhar da Educação Física.

Gradativamente foi sendo explicitado que o conhecimento escolar não é neutro, e que não é mais possível perceber e analisar de maneira ingênua a escola e os contextos em que são desenvolvidas as práticas pedagógicas e o trabalho docente.

Foi explicitado que o entendimento a respeito do PPP por parte das professoras de Educação Física não depende somente de um projeto individual de cada professor, mas também da busca coletiva de uma nova organização que considere cada escola, com suas particularidades e os contextos sociais próprios como base para elaboração e construção de um projeto.

A forma de pensar e conceber um PPP evidencia os diferentes focos de pensar a escola, a educação e a própria Educação Física, visto que este pensar está imbricado de elementos que caracterizam a fragmentação do processo educativo e da formação do professor, ou seja, organização escolar cristalizada - tempos e espaços pré-estabelecidos, conteúdos escolares não relevantes, pouca participação do aluno e do professor nos processos decisórios da escola, políticas públicas educacionais que não consideram as características de cada escola, formação inicial que não prepara o professor para realizar mudanças, dificuldades em considerar e constituir a escola também como espaço de formação continuada e local de articulação e integração de saberes.
No entanto, este estudo nos permite concluir ou refletir, que o entendimento a respeito do PPP considerando a formação dos professores, a Educação Física enquanto componente do currículo escolar e os contextos em que as práticas são desenvolvidas, podem se tornar incongruentes se, efetivamente o poder de decisão mantiver-se centralizado nas secretarias municipais ou estaduais.

As professoras não desconsideraram também que as escolas precisam compreender que detém autonomia legal para encaminhar propostas próprias, no entanto, requer maior envolvimento político e pedagógico de todos, para que ações propositivas e coletivas possam ser encaminhadas.

Esperamos que o processo participativo e colaborativo no qual se desenvolveu este estudo tenha desencadeado o aumento do nível de consciência do grupo de professoras, um dos princípios da pesquisaação (Betti, 2009; Bracht, Caparróz, Fonte, Frade, Paiva \& Pires, 2003). Ressaltamos que não há garantias de que as professoras de fato passarão a agir efetivamente de maneira diferente. Há apenas indícios de que isto poderá acontecer, pois cada contexto de trabalho exigirá das professoras condutas profissionais e pedagógicas diferenciadas. A quantidade de encontros, o número de professoras envolvidas, a experiência docente pode ser considerado fatores limitantes para o aprofundamento da temática. No entanto, o referencial metodológico do tipo pesquisa-ação enfatiza o envolvimento dos sujeitos para desencadear açóes a partir das problematizações feitas durante o processo.

As professoras demonstraram interesse em continuar com os encontros após o término da pesquisa, alegando ter sido extremamente positivo problematizar e discutir a escola, utilizando-se do referencial do tipo pesquisa-ação, o que reforça a necessidade de ampliar e ressignificar as políticas públicas de formação continuada dos professores de Educação Física e dos demais componentes curriculares, considerando o aumento das demandas educativas e profissionais.

Destacamos também, que é urgente repensar e organizar o espaço escolar a partir de uma 
perspectiva pedagógica, política e coletiva, para que as ações possam ter sentido e significado para os alunos e professores. Os currículos das instituiçôes formadoras também foram mencionados como importantes para compreender o propósito do trabalho coletivo, chamando a atenção também para outras investigaçôes sobre o tema. O PPP pode constituir-se como um legítimo instrumento para participação e envolvimento político e pedagógico dos professores, legitimar a Educação Física enquanto área de matriz pedagógica e nortear açôes coletivas no cotidiano escolar.

Vale lembrar que atualmente as quatro professoras que participaram da pesquisa continuam trabalhando com a Educação Física escolar. Uma foi convidada para trabalhar em uma das Coordenadorias de Educação da rede municipal de São Paulo na formação de professores; outra finalizou um curso complementação pedagógica em 2005 e acumula cargo de Coordenadora Pedagógica; a outra participante ingressou recentemente no Mestrado e faz parte de um grupo de estudos em Educação Física escolar em uma universidade pública e a quarta professora, que finaliza este texto, tem procurado manter contato sistemático com as demais, trabalha como professora na rede municipal de São Paulo e no Ensino Superior, e tem como foco atual de pesquisa no Doutorado explicitar a partir das experiências do trabalho coletivo desenvolvidas na escola na qual trabalha as perspectivas dos alunos com relação às aprendizagens nas aulas de Educação Física (VenÂNCIO \& BetTi, 2011).

As consideraçôes aqui apresentadas são reflexões realizadas a partir das análises conduzidas no decorrer do estudo a respeito da importância e entendimento do PPP e que poderão tornar-se pontos para encaminhamentos de novas discussões e proposiçóes para valorizar o trabalho realizado por professores de Educação Física envolvidos com o trabalho e práticas pedagógicas coletivas.

\title{
Notas
}

1. A temática desse artigo é parte da Dissertação de Mestrado defendida junto ao programa de Pós-Graduação em Ciências da Motricidade Humana/UNESP, campus de Rio Claro, em 2005.

2. A participação das professoras na pesquisa ocorreu mediante termo de consentimento livre e esclarecido.

A autora Luciana Venâncio é bolsista FAPESP, fazendo doutoramento em Educação / UNESP - Presidente Prudente - FCT.

\begin{abstract}
Physical education school and political pedagogical project: a collective construction process from the action-research standpoint

The purpose of this study is to present the understanding of a group of Physical Education female teachers, who work in elementary education in São Paulo's public schools, about the meaning of the Political Pedagogical Project (PPP) in the everyday practices. Besides, we tried to provide subsidies for the elaboration and development of a PPP, and point out the limits and possibilities of collective action within the school context. For this qualitative investigation we used one type of action-research as methodological referential. We have conducted an analysis of relevant works focusing on the PPP topic, in order to elaborate categories for a careful discussion about the selected theoretical framework. Results indicated that it is necessary to deepen meanings and readdress understandings of the school's function and its role, Physical Education's role as curriculum component, and also other curriculum components.' We highlighted the urgent need to rethink and organize the school from a pedagogical, political, and collective perspective, so that actions can have meaning and significance for students and teachers. The curricula of higher education institutions were also mentioned as important to comprehend the purpose of collective work. The PPP can establish itself as a legitimate instrument for Physical Education teachers' political and pedagogical participation and involvement, and to guide collective actions in the school every day practices.
\end{abstract}

UnITERMs: School physical education; Collective working; Teachers' education; Action-research. 


\section{Referências}

ALARCÃO, I. (Org.). Escola reflexiva e nova racionalidade. Porto Alegre: Artmed, 2001.

BETTI, M. A janela de vidro: esporte, televisão e educação física. Campinas: Papirus, 1998.

. Educação física escolar: ensino e pesquisa-ação. Ijuí: Unijuí, 2009.

BOURDIEU, P.; PASSERON, J.C. A reprodução: elementos para uma teoria do sistema de ensino. Rio de Janeiro: Francisco Alves, 1992.

BRACHT, V. Saber e fazer pedagógicos: acerca da legimitidade da educação física como componente curricular. In: CAPARROZ, F.E. (Org.). Educação física escolar. Vitória: Proteoria, 2001. v.1.

BRACHT, V.; CAPARRÓZ, F.E.; FONTE, S.S.D.; FRADE, J.C.; PAIVA, F.; PIRES, R. Pesquisa em ação: educação física na escola. Ijuí: Unijuí, 2003

BRASIL. Secretaria de Educação Fundamental. Parâmetros Curriculares Nacionais: educação física. Brasília: MEC/SEF, 1998. Ministério da Educação. Lei de Diretrizes e Bases da Educação Nacional no 9394, 1996. Brasilia: MEC,

1996. Disponível em: <http://www.mec.gov.br>. Acesso em: 9 set. 2004

CURY, C.R.J. As vozes da LDB. Presença Pedagógica, v.3, n.15, 1997.

DAOLIO, J. Da cultura do corpo. Campinas: Papirus, 2000.

ELLIOTT, J. Recolocando a pesquisa-ação em seu lugar original e próprio. In: GERALDI, C.M.G; FIORENTINI, D.; PEREIRA, E.M.A. (Orgs.). Cartografias do trabalho docente. Campinas: Mercado das Letras, 1998.

El cambio educativo desde la investigació-acción. Madri: Morata, 1993.

FREIRE, J.B. Educação de corpo inteiro. São Paulo: Scipione, 1989.

FREIRE, P. Política e educação. São Paulo: Cortez, 2001.

FRIGOTTO, G. A formação e a profissionalização do educador: novos desafios. In: SILVA, T.T.; GENTILI, P. (Orgs.).

Escola S.A. Rio de Janeiro: Vozes, 1996. p.75-166.

GADOTTI, M. Escola cidadã. São Paulo: Cortez, 2001.

IMBERNON, F. Formação docente profissional: formar-se para a mudança e a incerteza. São Paulo: Cortez, 2002.

KRAMER, S. Propostas pedagógicas ou curriculares: subsídios para uma leitura crítica. Educação e Sociedade, Campinas, n.60, p.15-35, 1997.

LIBÂNEO, J.C. Adeus professor, adeus professora?: novas exigências educacionais e profissão docente. São Paulo: Cortez, 1998. MOTA E SILVA, E.V.; VENÂNCIO, L. Aspectos legais da educação física e integração à proposta pedagógica da escola. In: DARIDO, S.C.; RANGEL, I.C. Educação física no ensino superior: implicações para a prática pedagógica. Rio de Janeiro: Guanabara Koogan, 2005. p.50-63.

NÓVOA, A. Os professores e sua formação. Lisboa: Dom Quixote, 1995.

PAES, R.R. A pedagogia do esporte e os jogos coletivos. In: DE ROSE JÚNIOR, D. Esporte e atividade física na infância e na adolescência: uma abordagem multidisciplinar. Porto Alegre: ArtMed, 2002.

PALMA FILHO, J.C. Cidadania e educação. Cadernos de Pesquisa, São Paulo, n.104, p.101-21, 1998.

RIOS, T.A. Ética e competência. São Paulo: Cortez, 1995.

SACRISTÁN, J.G. Poderes instáveis em educação. Porto Alegre: Artmed, 1999.

SANCHES NETO, L.; VENÂNCIO, L.; OKIMURA, T.; ULASOWICZ, C. Sistematização de conteúdos temáticos na Educação Física escolar: uma proposta de professores-pesquisadores. In: FONTOURA, P. (Ed.). Pesquisa em educação física. Jundiaí: Fontoura, 2006. v.4, p.270-4.

SOARES, C.L.; TAFFAREL, C.N.Z.; VARJAL, E.; CASTELLANI FILHO, F.; ESCOBAR, M.O.; BRACHT, V. Metodologia do ensino de educação física. São Paulo: Cortez, 1992.

THIOLLENT, M. Metodologia da pesquisa-ação. 10. ed. São Paulo: Cortez/Autores Associados, 2000.

VALE, J.M.F. Projeto político-pedagógico como instrumento coletivo de transformação do contexto escolar. In: BICUDO, M. A.V.; SILVA JUNIOR, C. (Orgs.) Formação do educador e avaliação educacional. São Paulo: UNESP, 1999. VEIGA, I.P.A. Escola: espaço de projeto político pedagógico. Campinas: Papirus, 1998.

Projeto político pedagógico da escola: uma construção possível. Campinas: Papirus, 1995.

VENÂNCIO, L. O projeto político-pedagógico e a educação física escolar: um processo de construção coletiva. 2005. Dissertação (Mestrado) - Universidade Estadual Paulista, Rio Claro, 2005a.

Projeto político pedagógico e a educação física escolar: uma prática pedagógica possível. In: BRASIL. Ministério da Educação. Coleção cotidiano escolar: a educação física no ensino fundamental (5a a $8^{a}$ série). Paidéia, Natal, v.1, n.1, 2005, p.114-27, 2005b.

108 • Rev. bras. Educ. Fís. Esporte, São Paulo, v.26, n.1, p.97-109, jan./ mar. 2012 
VENÂNCIO, L.; BETTI, M. Problem setting and reflections on one teacher-researcher's educational practice: may the students be subjects of the relationship with knowledge in physical education classes? In: ISATT BIENNIAL, 15., Braga, 2011. Proceedings... Minho: Universidade do Minho, 2011. 1 CD-ROM.

ENDEREÇO

Luciana Venâncio R. Siqueira Silva, 118 - Penha 03639-020 - São Paulo - SP - BRASIL e-mail: luciana_venancio@yahoo.com.br
Recebido para publicação: 15/02/2009

Revisado: 25/05/2011

Aceito: 03/ 02/ 2012 